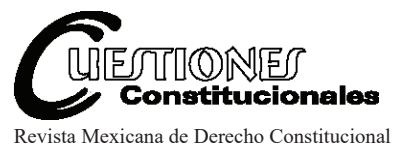

Núm. 38, enero-junio 2018

\title{
LA RELACIÓN ENTRE LA DOCTRINA DEL CONTROL DE CONVENCIONALIDAD Y EL DERECHO NACIONAL
}

\author{
THE RELATIONSHIP BETWEEN THE DOCTRINE \\ OF CONVENTIONALITY CONTROL AND DOMESTIC LAW
}

\section{Pablo GonzÁLez Domínguez}

RESUMEN: La doctrina del control de convencionalidad impone obligaciones internaciones a todas las autoridades de los Estados parte de la Convención Americana sobre Derechos Humanos. Sin embargo, esta doctrina está íntimamente relacionada con el derecho nacional. Este artículo explora esa relación, desde una perspectiva tanto descriptiva como normativa. En la primera parte, explica que el origen del control de convencionalidad se relaciona con el fenómeno de constitucionalización del derecho internacional de los derechos humanos en Latinoamérica, el cual ha tenido lugar en los últimos 30 años. En la segunda parte, argumenta que el entendimiento sobre la operatividad del control de convencionalidad debe depender de diversas normas y principios en los ordenamientos jurídicos nacionales. En consecuencia, el artículo propone una visión del control de convencionalidad que reconoce la existencia de legítimos espacios de autodeterminación constitucional en la manera en que éste opera en el ámbito estatal.

Palabras clave: control de convencionalidad, derecho internacional y derecho nacional, Corte Interamericana de Derechos Humanos, constitucionalismo latinoamericano.
ABSTRACT: The doctrine of conventionality control is the source of international obligations for all the authorities of the States parties to the American Convention on Human Rights. Yet, this doctrine is closely connected with domestic law. This article explores that relationship, both from a descriptive and a normative perspective. The first part explains how the origin of conventionality control is connected with the phenomenon of the constitutionalization of International Human Rights Law in Latin-America, which has taken place during the last thirty years. The second part argues that our understanding of the operability of conventionality control should depend on several norms and principles of domestic legal systems. Consequently, the article proposes a version of conventionality control that recognizes the existence of legitimate spaces of constitutional self-determination regarding how this doctrine operates at the state level.

Keywords: Conventionality Control, Relationship between International Law and Domestic Law, Inter-American Court of Human Rights, Latin-American Constitutionalism.

* Doctor en derecho internacional de los derechos humanos por la Universidad de Notre Dame; abogado en la Corte Interamericana de Derechos Humanos. 
SUMARIO: I. Introducción. II. El control de convencionalidad como parte del fenómeno de apertura del derecho constitucional latinoamericano. III. Aspectos normativos que determinan la operatividad del control de convencionalidad a nivel nacional. IV. El caso de México. V. Conclusión.

\section{INTRODUCCIÓN ${ }^{1}$}

El presente trabajo reflexiona en torno a la relación descriptiva y normativa que existe entre la doctrina del control de convencionalidad y el derecho constitucional de los Estados parte de la Convención Americana sobre Derechos Humanos. La primera parte explica esta relación desde una perspectiva descriptiva, es decir cómo el fenómeno de apertura del derecho constitucional al derecho internacional, ocurrido en diversos países de Latinoamérica en los últimos 30 años, fue relevante en la posición asumida por la Corte Interamericana de Derechos Humanos desde el caso Almonacid Arellano y otros vs. Chile (2006), donde la doctrina del control de convencionalidad fue formulada por primera ocasión. Por lo tanto, la primera parte de este trabajo tiene un objetivo modesto: contribuir a un mejor entendimiento de los factores que rodearon el surgimiento del control de convencionalidad en la jurisprudencia de la Corte Interamericana.

La segunda parte tiene una lógica y un objetivo distinto. Se encuadra en la discusión teórica que existe sobre si el control de convencionalidad - entendida como una doctrina de derecho internacional- presupone o afirma la supremacía de la Convención Americana y sus fuentes sobre el derecho constitucional. En este sentido, argumenta que el "principio de integración" no es parte esencial del control de convencionalidad, por lo que la "intensidad" que este control tiene en los diversos Estados de la región está normativamente ligada, tanto desde una perspectiva procesal como sustantiva, a diversas reglas y principios constitucionales, específicamente a aquellos que determinan: $a$ ) las competencias de las autoridades nacionales

1 Agradezco los comentarios de Luis Raúl Gutiérrez, Georgina Vargas, Martín Sánchez, Andrés López y Pier Pigozzi, así como los comentarios de los dos árbitros que comentaron este trabajo, los cuales fueron de inmensa ayuda para refinar cuestiones de forma y fondo. Las opiniones expuestas aquí son de mi propia autoría, y no necesariamente reflejan la posición oficial de la Corte Interamericana de Derechos Humanos, o la de mis colegas que lo comentaron. 
para realizar un control de constitucionalidad, b) el nivel de incorporación que las Constituciones de cada Estado le reconoce a las diferentes fuentes de derecho que integran el corpus juris interamericano, y c) el nivel de regulación constitucional que existe en relación con los derechos humanos.

En consecuencia, la segunda parte de este artículo defiende la tesis que afirma que el control de convencionalidad reconoce $-\mathrm{o}$ debe reconocer- la existencia de legítimos y amplios espacios de autodeterminación constitucional en la manera en que éste debe operar en el ámbito estatal. Se trata de una posición que sostiene que, aun cuando el control de convencionalidad imponga una obligación directa para todas las autoridades del Estado de aplicar las fuentes del derecho internacional a nivel interno, específicamente la Convención Americana y las interpretaciones que de ella haga la Corte Interamericana, esto no significa que esta aplicación del derecho internacional no esté legítimamente relativizada (o regulada) por el derecho constitucional. Es en el contexto de esta discusión que al final de este artículo se hacen algunas referencias a la recepción que el derecho constitucional mexicano ha hecho del control de convencionalidad.

\section{El CONTROL DE CONVENCIONALIDAD COMO PARTE DEL FENÓMENO} DE APERTURA DEL DERECHO CONSTITUCIONAL LATINOAMERICANO

La Corte Interamericana desarrolló la doctrina del control de convencionalidad de manera pretoriana en Almonacid Arellano, como "una garantía destinada a obtener la aplicación armónica del derecho vigente". ${ }^{2}$ La Corte Interamericana se ha referido a esta doctrina como "una institución que se utiliza para aplicar el derecho internacional, en este caso el de los derechos humanos, y específicamente la Convención Americana y sus fuentes, incluyendo la jurisprudencia de este Tribunal". ${ }^{3}$ De manera más reciente, en Andrade Salmón vs. Bolivia (2016) la Corte explicó que el control de convencionalidad busca que "la interpretación y aplicación del derecho nacional sea consistente con las obligaciones internacionales del Estado

\footnotetext{
2 Albanese, Susana, "La internacionalización del derecho constitucional y la constitucionalización del derecho internacional", en Albanese, Susana (coord.), El control de convencionalidad, Buenos Aires, Ediar, 2008, p. 15.

3 Cfr. Corte IDH. Caso Gelman vs. Uruguay. Supervisión de Cumplimiento de Sentencia. Resolución de la Corte Interamericana de Derechos Humanos, pfo. 65, 20 de marzo de 2013.
} 
en materia de derechos humanos". ${ }^{4}$ En el mismo sentido, Eduardo Ferrer MacGregor ha definido el control de convencionalidad como:

Una obligación internacional a cargo de todas las autoridades de los Estados parte del Pacto de San José de interpretar cualquier norma nacional (Constitución, ley, decreto, reglamento, jurisprudencia, etcétera) de conformidad con la Convención Americana y, en general, con el corpus juris interamericano; en caso de que exista una manifiesta incompatibilidad entre la norma nacional y el corpus iuris interamericano, las autoridades estatales deberán abstenerse de aplicar la norma nacional para evitar la vulneración de los derechos humanos protegidos internacionalmente. Las autoridades estatales deben ejercer de oficio el control de convencionalidad, pero siempre actuando dentro de sus respectivas competencias y de las regulaciones procesales correspondientes, las cuales se definen en el ámbito interno. ${ }^{5}$

Sin embargo, a pesar de su origen y desarrollo en la jurisprudencia de la Corte Interamericana, el control de convencionalidad no fue concebido en abstracto. Su creación y diseño está relacionado con lo que Sergio García Ramírez llama el "complejo universo de las relaciones entre los órganos internacionales (particularmente la Corte) y los sistemas nacionales". ${ }^{6}$ Este "complejo universo" ha estado marcado por la construcción de "puentes" que han mitigado el conflicto entre "el imperio del orden jurídico nacional y el dominio del orden jurídico internacional". ${ }^{7}$ Estos puentes han operado en diversos niveles: normativo, político y práctico. ${ }^{8}$ El primero se ha manifestado en la apertura de los Estados que han reconocido la jerarquía constitucional de las normas de derechos humanos contenidas en tratados internacionales, lo cual ha permitido la primacía de los derechos humanos

4 Caso Andrade Salmón vs. Bolivia. Fondo, reparaciones y costas. Sentencia del 1o. de diciembre de 2016, serie C, núm. 330, pfo. 93.

5 Cfr. Ferrer MacGregor, Eduardo, "Control de convencionalidad (sede interna)", en Ferrer MacGregor, Eduardo et al., Diccionario de derecho procesal constitucional y convencional, México, Poder Judicial de la Federación, Consejo de la Judicatura FederalUNAM, Instituto de Investigaciones Jurídicas, 2014, vol. I, p. 233.

6 García Ramírez, Sergio, "The Relationship Between Inter-American Jurisdiction and States (National Systems): Some Pertinent Questions", Notre Dame Journal of International and Comparative Law, 2015, vol. 1, Iss. 1, artículo 2o., p. 122.

7 Ibidem, p. 125.

8 Ibidem, p. 126, en los párrafos siguientes, sólo serán abordados dos de los puentes normativos a los que se refiere García Ramírez. 
(de fuente nacional o internacional) en relación con todas las normas secundarias de un determinado ordenamiento jurídico nacional. ${ }^{9}$ Ejemplos de este tipo de aproximación se pueden observar en las Constituciones de Argentina, ${ }^{10}$ Bolivia, ${ }^{11}$ Brasil, ${ }^{12}$ Colombia,${ }^{13}$ Guatemala, ${ }^{14}$ México, ${ }^{15}$ Panamá, ${ }^{16}$ Perú ${ }^{17}$ y Uruguay. ${ }^{18}$ Por ejemplo, el artículo 46 de la Constitución de Guatemala establece —en su parte relevante — lo siguiente:

Artículo 46. Preeminencia del derecho internacional. Se establece el principio general de que en materia de derechos humanos, los tratados convencionales aceptados y ratificados por Guatemala, tienen preeminencia sobre el derecho interno. ${ }^{19}$

El segundo es el jurisdiccional. ${ }^{20}$ Ha sido construido a través de las decisiones de las Supremas Cortes de Justicia o los Tribunales Constitucionales de varios Estados parte de la Convención Americana, las cuales han interpretado sus textos constitucionales para hacer posible la incorporación de las normas del derecho internacional de derechos humanos y de las interpretaciones de la Corte Interamericana como parte del derecho

9 Ibidem, pp. 127 y 128; cfr. Uprimny, Rodrigo, "The Recent Transformation of Constitutional Law in Latin America: Trends and Challenges", Texas Law Review, núm. 89, 2010-2011, p. 1591; Góngora Mena, Eduardo, Inter-American Judicial Constitutionalism: On the Constitutional Rank of Human Rights Treaties in Latin-America Through National and Inter-American Adjudication, Costa Rica, IIDH, 2011, p. 243.

10 Constitución Política de Argentina, 1o. de mayo de 1853, artículo 75.22.

11 Constitución Política del Estado Plurinacional de Bolivia, 7 de febrero de 2009, artículos 13.II, 13.IV y 256.

12 Constitución de la República Federativa de Brasil, 5 de octubre de 1988, artículo 5o. LXXVI.2.

13 Constitución Política de Colombia, julio de 1991, artículo 93.

14 Constitución Política de la República de Guatemala, 31 de mayo de 1985, artículo 46.

15 Constitución Política de los Estados Unidos Mexicanos, 5 de febrero de 1917, artículo 10 .

16 Constitución Política de la República de Panamá, 11 de octubre de 1972, artículo 17.

17 Constitución Política del Perú, 29 de diciembre de 1993, artículos transitorios 3o. y 4 o.

18 Constitución de la República Oriental del Uruguay, 1967, artículo 72.

19 Constitución Política de la República de Guatemala, 1993, artículo 46.

20 Cfr. García Ramírez, Sergio, "The Relationship...”, cit., p. 133; García Sayán, Diego, "The Inter-American Court and Constitutionalism in Latin-America", Texas Law Review, Estados Unidos de América, núm. 89, 2010-2011, p. 1838. 
nacional. ${ }^{21}$ Esta tendencia fue mencionada en Cabrera García y Montiel Flores vs. México (2010), donde la Corte Interamericana hizo referencia a las decisiones de la Sala Constitucional de la Suprema Corte de Justicia de Costa Rica, ${ }^{22}$ la Corte Constitucional de Bolivia, ${ }^{23}$ la Corte Suprema de Justicia de República Dominicana, ${ }^{24}$ el Tribunal Constitucional de Perú, ${ }^{25}$ la Suprema Corte de Justicia de Argentina, ${ }^{26}$ y la Corte Constitucional Colombiana. ${ }^{27}$ Estas Cortes y Tribunales "progresivamente han privilegiado interpretaciones dinámicas que favorecen y posibilitan la recepción de los derechos humanos previstos en los tratados internacionales", fortaleciendo así el fenómeno de apertura constitucional hacia la aceptación de los estándares del corpus juris interamericano. ${ }^{28}$

Algunos ejemplos en la región permiten observar cómo se ha manifestado este fenómeno.

El Tribunal Constitucional del Perú (TCP) reconoció que los tratados internacionales sobre derechos humanos y las interpretaciones de la Corte Interamericana son fuentes de derecho relevantes para la determinación del contenido de los derechos fundamentales reconocidos por la Constitución del Perú, la cual establece en su artículo 55 que "[1]os tratados celebrados

21 Corte IDH. Caso Cabrera García y Montiel Flores vs. México. Excepción preliminar, fondo, reparaciones y costas. Sentencia del 26 de noviembre de 2010, serie C, núm. 220, pfos. 226-232.

22 Sentencia del 9 de mayo de 1995 emitida por la Sala Constitucional de la Corte Suprema de Justicia de Costa Rica, Acción Inconstitucional, voto 2313-95 (expediente 0421-S-90), considerando VII.

23 Sentencia emitida el 10 de mayo de 2010 por el Tribunal Constitucional de Bolivia (expediente núm. 2006-13381-27-RAC), apartado III.3. sobre "El Sistema Interamericano de Derechos Humanos. Fundamentos y efectos de las Sentencias emanadas de la Corte Interamericana de Derechos Humanos".

24 Resolución núm. 1920-2003 emitida el 13 de noviembre de 2003 por la Suprema Corte de Justicia de República Dominicana.

25 Sentencia emitida el 21 de julio de 2006 por el Tribunal Constitucional del Perú (expediente núm. 2730-2006-PA/TC), fundamento 12.

26 Sentencia emitida el 23 de diciembre de 2004 por la Corte Suprema de Justicia de la Nación, República Argentina (expediente 224. XXXIX), "Espósito, Miguel Ángel s/ incidente de prescripción de la acción penal promovido por su defensa", considerando 6 .

27 Sentencia C-010/00 emitida el 19 de enero de 2000 por la Corte Constitucional de Colombia, pfo. 6 .

28 Corte IDH, Caso Cabrera García y Montiel Flores vs. México..., cit., nota 21, voto concurrente del juez Eduardo Ferrer Mac-Gregor, pfo. 26; cfr. García Ramírez, Sergio, "The Relationship...", cit., nota 6, pp. 133 y 134. 
por el Estado y en vigor forman parte del derecho nacional", ${ }^{29}$ y establece en la Cuarta Disposición Final y Transitoria que "[1]as normas relativas a los derechos y a las libertades que la Constitución reconoce se interpretan de conformidad con la Declaración Universal de los Derechos Humanos $\mathrm{y}$ con los tratados y acuerdos internacionales sobre las mismas materias ratificados por el Perú". ${ }^{30}$

En tal sentido, el TCP concluyó que los tratados internacionales no sólo son parte del ordenamiento jurídico nacional, sino que los poderes públicos nacionales deben incorporar los ámbitos normativos de los tratados y las interpretaciones de la Corte Interamericana a través de un ejercicio hermenéutico. ${ }^{31}$ En pablaras del TCP:

se trata de un reconocimiento implícito de la identidad nuclear sustancial compartida por el constitucionalismo y el sistema internacional de protección de los derechos humanos: la convicción jurídica del valor de la dignidad de la persona humana, a cuya protección y servicio se reconduce, en última y definitiva instancia, el ejercicio de todo poder. ${ }^{32}$

La Constitución Política de Costa Rica establece en su artículo 7o. que "los tratados públicos, los convenios internacionales y los concordatos debidamente aprobados por la Asamblea Legislativa, tendrán desde su promulgación o desde el día que ellos designen, autoridad superior a las leyes". ${ }^{33}$ El artículo 48 establece que "[t]oda persona tiene recurso... de amparo para mantener el goce de los otros derechos consagrados en esta Constitución, así como de los de carácter fundamental establecidos en los instrumentos internacionales sobre derechos humanos, aplicables a la República". ${ }^{34}$ La Sala Constitucional de la Suprema Corte de Justicia (CCCR) interpretó estas disposiciones en el caso 0421-S-90 (1995) estableciendo que los instrumentos de derechos humanos vigentes en Costa Rica priman sobre la Constitución en aquellos casos que otorguen mayores derechos, y que las interpretaciones de la Corte Interamericana — como el

\footnotetext{
29 Constitución Política del Perú, artículo 55.

30 Ibidem, cuarta disposición final y transitoria.

31 Sentencia emitida el 21 de julio de 2006 por el Tribunal Constitucional del Perú (expediente núm. 2730-2006-PA/TC), pfos. 9 y 11.

32 Ibidem, pfo. 9.

33 Constitución Política de Costa Rica, artículo 7o.

34 Ibidem, artículo 48.
} 
órgano natural para interpretar la Convención Americana — tienen el mismo valor de la norma interpretada. ${ }^{35}$ En consecuencia, determinó el CCCR, en el ordenamiento jurídico costarricense, las normas no escritas - como las interpretaciones de la Corte Interamericana - tendrán el rango de la norma de la que derivan. ${ }^{36}$

La Constitución Política de Colombia establece en su artículo 93 que "los tratados y convenios internacionales ratificados por el Congreso, que reconocen los derechos humanos y que prohíben su limitación en los estados de excepción, prevalecen en el orden interno". ${ }^{37} \mathrm{El}$ mismo artículo también establece que "[1]os derechos y deberes consagrados en esta carta, se interpretarán de conformidad con los tratados internacionales sobre derechos humanos ratificados por Colombia". ${ }^{38}$ En la interpretación del artículo 93, la Corte Constitucional Colombiana (CCC) determinó en el caso C-010/00 que "es indudable que la jurisprudencia de las instancias internacionales, encargadas de interpretar esos tratados, constituye un criterio hermenéutico relevante para establecer el sentido de las normas constitucionales sobre derechos fundamentales". ${ }^{39}$ Sin embargo, aun cuando la CCC ha reconocido la relevancia de las interpretaciones de la Corte Interamericana para determinar el alcance de los derechos fundamentales en el ordenamiento jurídico colombiano, esto no significa que dichas interpretaciones constituyan fuentes primarias de derechos y obligaciones. ${ }^{40}$

La Constitución Política de la Nación Argentina reconoce en su artículo 75.22 una lista de instrumentos internacionales en materia de derechos humanos —incluida la Convención Americana — que tienen jerarquía constitucional. ${ }^{41}$ Los derechos reconocidos en estos instrumentos internacionales son complementarios a los derechos protegidos por la Constitución,

35 Sentencia de 9 de mayo de 1995 emitida por la Sala Constitucional de la Corte Suprema de Justicia de Costa Rica. Acción Inconstitucional, voto 2313-95 (Expediente 0421-S-90), pfos. VI y VII.

36 Ibidem, pfo. VII.

37 Constitución Política de Colombia, artículo 93.

38 Ibidem.

39 Sentencia C-010/00 emitida por la Corte Constitucional de Colombia, pfo. 70.

40 Fajardo, Luis Andrés, Implementación del Sistema Interamericano de Derechos Humanos en Colombia a través del bloque de constitucionalidad, serie documentos de investigación en derecho, núm. 11, Diké, 2010, p. 129.

41 Constitución de la Nación Argentina, artículo 75.22. 
significando lo que se puede denominar el "bloque de la constitucionalidad federal". ${ }^{42}$

La apertura del derecho constitucional argentino se ha reflejado en las decisiones de la Corte Suprema de Justicia de la Nación Argentina (CSJNA). En Ekmekdjan c/ Sofovic (1992) la CSJNA estableció que "la interpretación del Pacto [de San José] debe, además, guiarse por la jurisprudencia de la Corte Interamericana de Derechos Humanos, uno de cuyos objetivos es la interpretación del Pacto de San José". ${ }^{43}$ Esta misma apertura a la utilización de la jurisprudencia de la Corte puede verse en Mazzeo, Julio Lilo y otros (2007), donde la CSJNA se refirió expresamente a la doctrina del control de convencionalidad para — entre muchos elementos - determinar la inconstitucionalidad del decreto del Poder Ejecutivo 1002/89. ${ }^{44}$

La creación del control de convencionalidad está íntimamente vinculada con el fenómeno antes descrito. ${ }^{45}$ Este fenómeno refleja la voluntad política del legislador de adoptar normas constitucionales que permiten una incorporación cada vez más amplia del corpus juris interamericano a nivel nacional, así como la convicción del Poder Judicial en varios Estados sobre la posibilidad de utilizar los estándares del corpus juris interamericano en la resolución de casos que involucran la protección a derechos humanos. La Corte Interamericana recibió el influjo de los cambios en el constitucionalismo latinoamericano, condición que ayuda a explicar la creación del control de convencionalidad como un nuevo "puente" (utilizando el lenguaje de García Ramírez) o como una "medida de otro carácter" (utilizando el lenguaje del artículo 2o. de la Convención Americana) para garantizar la efectividad de los derechos humanos a nivel nacional. En palabras de Ferrer Mac-Gregor:

Resulta evidente que la Corte IDH crea la doctrina del "control difuso de convencionalidad" advirtiendo la tendencia de la "constitucionalización" o, si se prefiere, "nacionalización" del "derecho internacional de los derechos

42 Gil Domínguez, Andrés, "El bloque de la constitucionalidad federal y los informes de la Comisión Interamericana de Derechos Humanos", Revista Argentina de Derecho Constitucional, Argentina, año 2, 2001, p. 58.

43 Sentencia de la Corte Suprema de la Nación de Argentina, Ekmekdjan c/Sofovic, 7 de julio de 1992, pfo. 21.

44 Sentencia de la Corte Suprema de Justicia de la Nación de Argentina, Mazzeo, Julio Lilo y otros, 13 de julio de 2007, pfos. 20 y 21.

45 García Ramírez, Sergio, "The Relationship...", cit., p. 137. 
humanos" y particularmente la aceptación de su jurisprudencia convencional como elemento "hermenéutico" y de "control" de la normatividad interna por parte de los propios tribunales internos; es decir, la Corte IDH recibió el influjo de la práctica jurisprudencial de los jueces nacionales para crear la nueva doctrina sobre el "control difuso de convencionalidad. ${ }^{46}$

\section{ASPECTOS NORMATIVOS QUE DETERMINAN LA OPERATIVIDAD}

DEL CONTROL DE CONVENCIONALIDAD A NIVEL NACIONAL

\section{El principio de integración}

No parece existir controversia sobre la relación que existe entre la tendencia iniciada por las Constituciones latinoamericanas hace más de veinte o treinta años y la creación del control de convencionalidad. Sin embargo, una versión extrema del control de convencionalidad parecería afirmar que esta relación no sólo es descriptiva (es decir que no sólo explica su surgimiento, como se ha dicho en este texto), sino que además tiene importantes consecuencias normativas. En este sentido, Ariel E. Dulitzky afirma que la creación del control de convencionalidad incluyó el desarrollo del "principio de integración" (integration principle) ${ }^{47}$ Este principio transformaría la Convención Americana y las interpretaciones de la Corte Interamericana en una parte integral de los sistemas jurídicos nacionales, otorgándoles la más alta jerarquía. ${ }^{48}$

Bajo esta óptica, la creación del control de convencionalidad en Almonacid Arellano incluyó la determinación de que la Convención Americana y las interpretaciones de la Corte (y en general el contenido del corpus juris interamericano) tienen efecto directo y son supremos a cualquier norma de derecho nacional, por lo que los jueces deben preferir siempre el derecho internacional sobre el derecho nacional en la solución de casos sujetos a su jurisdicción. ${ }^{49}$ Esta interpretación sin duda es una versión extrema de

\footnotetext{
46 Corte IDH. Caso Cabrera García y Montiel Flores vs. México..., cit., voto concurrente del juez Eduardo Ferrer Mac-Gregor, pfo. 29.

47 Cfr. Dulitzky, Ariel E., “An Inter-American Constitutional Court? The Invention of Conventionality Control by the Inter-American Court of Human Rights", Texas International Law Journal, Estados Unidos de América, 50, 2015, pp. 56 y 54.

48 Ibidem, p. 54.

49 Ibidem, p. 57.
} 
la fuerza normativa del corpus juris interamericano, y aun así podría ser correcta. La doctrina del control de convencionalidad podría incluir, en su génesis, el principio de integración. Esto significaría que, desde la resolución de Almonacid Arellano, el corpus juris interamericano adquirió jerarquía supra-constitucional en todos los Estados parte de la Convención Americana, independientemente de si esta jerarquía es reconocida por los textos constitucionales de dichos Estados.

Sin embargo, esta interpretación debe ser tratada como una hipótesis, pues no es la única forma posible —y tampoco la más razonable, en opinión de quien escribe - de interpretar la línea jurisprudencial de la Corte Interamericana con relación al control de convencionalidad. Es también posible interpretarla de forma que el control de convencionalidad se base en la idea de que el corpus juris interamericano tiene efecto directo en el derecho nacional, pero no que es supremo. Si esto es posible, el control de convencionalidad presupondría que los Estados conservan su libertad de determinar la jerarquía del derecho internacional a nivel nacional, y para determinar algunos aspectos sustantivos sobre el contenido de algunos derechos humanos, aun cuando tienen la obligación de efectivamente aplicar el derecho internacional en la resolución de casos concretos. Tres argumentos soportan esta hipótesis alternativa a la planteada en la explicación de Dulitzky.

El primero es que el lenguaje que la Corte utilizó en Almonacid reconoce con claridad el efecto directo de la Convención Americana y las interpretaciones de la Corte, pero no necesariamente establece la supremacía de estas fuentes..$^{50} \mathrm{La}$ idea de que las normas de la Convención Americana tienen efecto directo es el resultado de que los Estados han ratificado el Pacto de San José, y de que "el objeto y razón de ser de una Convención de Derechos Humanos, así como la clara intensión de sus autores es reconocer a favor de individuos, como terceros beneficiarios, ciertos derechos y libertades". ${ }^{51}$ Esto significa que todas las autoridades tienen la responsabilidad de aplicar

50 Corte IDH. Caso Almonacid Arellano y otros vs. Chile. Excepciones preliminares, fondo, reparaciones y costas. Sentencia de 26 de septiembre de 2006, serie C, núm. 154, pfo. 124 ["Pero cuando un Estado ha ratificado un tratado internacional como la Convención Americana, sus jueces, como parte del aparato del Estado, también están sometidos a ella, lo que les obliga a velar por que los efectos de las disposiciones de la Convención no se vean mermadas por la aplicación de leyes contrarias a su objeto y fin, y que desde un inicio carecen de efectos jurídicos"].

51 Jiménez de Aréchaga, Eduardo, "La Convención Americana de Derechos Huma- 
el derecho internacional, y así velar para que los efectos de la Convención Americana no se vean mermados por la aplicación de normas contrarias a su objeto y fin. Por esta razón, solicitarle a las autoridades que realicen una interpretación conforme, o que dejen de aplicar una norma de derecho nacional cuando tengan competencia para hacerlo, no implica asumir sin más la supremacía de la norma específica que se utiliza como parámetro para efectuar dicho control. Significa solicitarle a las autoridades nacionales que cumplan con sus obligaciones de derecho internacional de una manera específica, pero en la medida que las normas de derecho internacional y nacional aplicables lo permitan.

El segundo es que los artículos 1.1 y 2o. de la Convención Americana pueden ser interpretados como la fuente de obligaciones directas para los Estados, pero difícilmente pueden ser considerados la base para argumentar la supremacía de la Convención. Es razonable argumentar que las normas de la Convención tienen efecto directo y que por lo tanto deben impactar la conducta de las autoridades cuando éstas deben aplicar el derecho nacional, toda vez que el artículo 1.1 reconoce el deber de los Estados de "respetar" y "garantizar" los derechos y libertades reconocidos por la Convención, y porque el artículo 2o. establece la obligación de adoptar las "medidas legislativas y de otro carácter" necesarias para hacer efectivos dichos derechos y libertades. Pero es fundamental considerar que el artículo 2o. debe ser cumplido "con arreglo a [los] procedimientos constitucionales y a las disposiciones de [la] Convención". ${ }^{52}$ Esto significa que la obligación de las autoridades de realizar un control de convencionalidad como una "medida de otro carácter" debe ser entendida a la luz de las reglas de derecho constitucional que definen la jerarquía del derecho internacional como derecho nacional, pues el artículo 2o. reconoce que la determinación de la jerarquía constitucional de la Convención es una facultad reservada a los Estados.

El tercero es que resulta razonable suponer que el control de convencionalidad debe operar dependiendo del nivel de participación de un Estado en concreto en la tendencia a la constitucionalización del derecho internacional de los derechos humanos en la región. La Corte Interamericana creó el control de convencionalidad en consideración a la tendencia de la incorporación del derecho internacional de los derechos humanos en el derecho

nos como derecho interno", Boletín da Sociedade Brasileira de Direito Internacional, Brasilia, núms. 69-71, 1987-1989, p. 32.

52 Convención Americana sobre Derechos Humanos, suscrita en San José, Costa Rica, 7 al 22 de noviembre de 1969, artículo 2o. 
nacional de varios países latinoamericanos, lo cual permitió la creación de un puente - entre otros puentes - para incrementar la efectividad del corpus juris interamericano a nivel nacional. Pero una cosa es crear una institución jurídica en el contexto de una tendencia general que fluye en la misma dirección, y otra es notar una tendencia y luego transformar radicalmente la Convención Americana y las interpretaciones de la Corte en la ley suprema de los Estados. Por esta razón es lógico considerar que la intensidad del control de convencionalidad debe depender de la manera en que los Estados han incorporado el derecho internacional a nivel nacional, y no considerar que el control de convencionalidad es una doctrina que ha hecho irrelevantes las normas de derecho constitucional que definen la jerarquía del corpus juris interamericano en el ordenamiento jurídico de los Estados.

Una vez explicada la hipótesis de que el principio de integración — con su presupuesto de la supremacía de la Convención - no es una parte esencial del control de convencionalidad, es posible abordar cuáles son aquellos elementos de derecho nacional que determinan la operatividad del control de convencionalidad en los diferentes Estados parte de la Convención. Estos elementos podrían definir en el futuro, tanto en la teoría como en la práctica, de lo que Ferrer Mac-Gregor ha llamado las diversas "intensidades" del control de convencionalidad, es decir los elementos normativos que "gradúan" los efectos del control de convencionalidad en un Estado determinado. ${ }^{53}$ Se advierte que éste es uno de los temas menos explorados en los estudios sobre el control de convencionalidad, pero que sin duda es fundamental para entender la operación de esta doctrina en los diversos Estados de la región. Las siguientes líneas buscan contribuir al entendimiento de los aspectos normativos de derecho nacional que determinan la operación del control de convencionalidad a nivel nacional. ${ }^{54}$

\section{La "cláusula Aguado Alfaro"}

Una de las características centrales del control de convencionalidad es que éste debe ser ejercido ex officio por todas las autoridades, es decir "con

53 Cfr. Corte IDH. Caso Cabrera García y Montiel Flores vs. México..., cit., nota 21, voto concurrente del juez Eduardo Ferrer Mac-Gregor, pfos. 34-37.

54 Cfr. González Domínguez, Pablo, "La doctrina del control de convencionalidad a la luz del principio de subsidiariedad", Estudios Constitutionales, Chile, año 15, núm. 1, 2017 , pp. 89-91. Este punto puede ser leído de manera conjunta con la publicación antes referida. 
independencia de que las partes lo invoquen". ${ }^{55}$ En la tesis de la Corte Interamericana, todas las autoridades de cada uno de los Estados deben estar conscientes del contenido de las normas del corpus juris interamericano, y deben utilizar estas fuentes en la forma y en la medida que sea pertinente para garantizar su efecto útil. En virtud de este principio, el Estado debe tomar una actitud garantista, previniendo que se produzcan violaciones a los derechos humanos de las personas sujetas a su jurisdicción a causa de formalismos excesivos. Sin embargo, la incorporación del principio iura novit curia al control de convencionalidad no pretende dar una carta blanca para ignorar el derecho nacional.

Desde Trabajadores cesados del Congreso (Aguado Alfaro y otros) vs. Perú (2006) la Corte estableció que el control de convencionalidad debe ser ejercido por las autoridades "en el marco de sus respectivas competencias y de las regulaciones procesales correspondientes" (lo que puede ser nombrado la "cláusula Aguado Alfaro"). ${ }^{56}$ Este elemento establece el primer límite para ejercer el control de convencionalidad ex officio, de forma tal que las autoridades no pueden actuar más allá de las facultades y las competencias que les otorga la legislación nacional. En consecuencia, la doctrina del control de convencionalidad es atenta al régimen de legalidad al que responden todas las autoridades nacionales, ${ }^{57}$ pues en principio no altera la facultad exclusiva de los Estados de decidir la forma en que organizan los poderes y atribuciones del Poder Judicial —o cualquier otra autoridad - para realizar control de constitucionalidad, ni altera las reglas procesales a nivel nacional. ${ }^{58}$

55 Corte IDH. Caso Trabajadores Cesados del Congreso (Aguado Alfaro y otros) vs. Perú. Excepciones preliminares, fondo, reparaciones y costas. Sentencia del 24 de noviembre de 2006, serie C, núm. 158, pfo. 128; Corte IDH. Caso Cabrera García y Montiel Flores vs. México..., cit., voto concurrente del juez Eduardo Ferrer Mac-Gregor Poisot, pfo. 42.

56 Corte IDH. Caso Trabajadores Cesados del Congreso (Aguado Alfaro y otros) vs. Perú..., cit., pfo. 128.

57 García Ramírez, Sergio, "El control judicial interno de convencionalidad", IUS Revista del Instituto de Ciencias Jurídicas de Puebla, 2011, año 5, núm. 28, pp. 54 y 65.

58 Londoño Lázaro, María Margarita, "El principio de legalidad y el control de convencionalidad de las leyes: confluencias y perspectivas en el pensamiento de la Corte Interamericana de Derechos Humanos", Boletín Mexicano de Derecho Comparado, México, núm. 128, p. 806. 
Uno de los principales objetivos de la "cláusula Aguado Alfaro" es que el control de convencionalidad pueda operar en diferentes sistemas jurídicos. ${ }^{59}$ Esto significa que en los Estados donde las autoridades (y especialmente los jueces) tienen mayores atribuciones de ejercer control de constitucionalidad, la obligación de ejercer un control de convencionalidad será más intensa que en aquellos sistemas donde dichas autoridades tienen menos atribuciones, o donde las regulaciones procesales son más estrictas. ${ }^{60}$ En este sentido, es posible afirmar que la Corte Interamericana no obliga a los Estados a establecer un sistema difuso o concentrado de control de constitucionalidad. ${ }^{61}$ Por lo que es razonable suponer que en países donde se ha establecido un control difuso de constitucionalidad que autoriza a todos los jueces a inaplicar normas inconstitucionales, el control de convencionalidad será ejercido con mayor intensidad que en países con características distintas. ${ }^{62}$ En palabras de la Corte en Liakat Ali Alibux vs. Surinam (2014):

124. Finalmente, en relación con los argumentos del representante y de la Comisión (supra pfos. 112 y 113) sobre la vulneración del derecho a la protección judicial con motivo de la ausencia de un Tribunal Constitucional, si bien la Corte reconoce la importancia de estos órganos como protectores de los mandatos constitucionales y los derechos fundamentales, la Convención Americana no impone un modelo específico para realizar un control de constitucionalidad y convencionalidad. En este sentido, la Corte recuerda que la obligación de ejercer un control de convencionalidad entre las normas internas y la Convención Americana le compete a todos los órganos del Estado, incluidos sus jueces y demás órganos vinculados a la administración de justicia en todos los niveles. ${ }^{63}$

59 Cfr. Corte IDH. Caso Cabrera García y Montiel Flores vs. México..., cit., voto concurrente del juez Eduardo Ferrer Mac-Gregor Poisot, pfos. 36 y 37.

60 Cfr. Sagués, Néstor Pedro, “Obligaciones Internacionales y Control de Convencionalidad”, Estudios Constitucionales, Chile, año 8, núm. 1, 2010, p. 121; cfr. Corte IDH. Caso Cabrera García y Montiel Flores vs. México, idem.

61 Cfr. García Ramírez, Sergio, "El control...", cit., nota 57, p. 152; cfr. Corte IDH. Caso Liakat Ali Alibux vs. Surinam. Excepciones preliminares, fondo, reparaciones y costas, sentencia del 30 de enero de 2014, serie C, núm. 276, pfo. 124.

62 Cfr. Hitters, Juan Carlos, "Control de constitucionalidad y control de convencionalidad. Comparación (criterios fijados por la Corte Interamericana de Derechos Humanos)", Estudios Constitucionales, año 7, núm. 2, 2009, pp. 109-128.

63 Corte IDH. Caso Liakat Ali Alibux vs. Surinam. Excepciones preliminares, fondo, reparaciones y costas, sentencia del 30 de enero de 2014, serie C, núm. 276, pfo. 124. 
Lo mismo se puede decir - aunque la Corte no se ha pronunciado al respecto- de aquellos Estados que sólo permiten a los jueces pronunciarse sobre lo que argumenten las partes en un procedimiento. Si existe una prohibición expresa para las autoridades - y en especial los jueces- de actuar conforme al principio iura novit curia, es razonable asumir que las normas de derecho internacional serán relevantes en la resolución de un caso en que las partes lo soliciten en el momento procesal oportuno. Por lo tanto, aunque haya Estados que puedan tener estas restricciones, como lo han hecho notar algunos tratadistas, ${ }^{64}$ esto no necesariamente significa que la obligación de las autoridades de realizar un control de convencionalidad ex officio implique actuar en contra del derecho nacional. Las autoridades deberán llevar a cabo este tipo de control ahí donde el derecho nacional se los permita, pues deben actuar dentro de sus respectivas competencias y de las regulaciones procesales correspondientes. Éste es al menos una manera de interpretar el sentido del fallo en Aguado Alfaro, donde la Corte Interamericana determinó que los tribunales peruanos tenían la facultad para inaplicar la norma violatoria de los derechos de las víctimas, y por lo tanto debieron realizar un control de convencionalidad ex officio. ${ }^{65}$

La "cláusula Aguado Alfaro" es un elemento fundamental para entender la naturaleza y diseño del control de convencionalidad. No tomar seriamente en consideración las implicaciones que tiene esta cláusula, puede llevar a concluir que la Corte está otorgando competencias a los jueces nacionales para evitar la aplicación del derecho nacional cuando éste es inconvencional, y que por lo tanto está imponiendo un sistema de control difuso de constitucionalidad y convencionalidad en todos los Estados parte de la Convención. ${ }^{66}$ Pero éstas son precisamente algunas de las cuestiones que la Corte Interamericana trató de evitar - aunque no sin problemas - desde su decisión en Aguado Alfaro. Por lo tanto, sí es posible afirmar que todas las autoridades tienen el deber siempre de aplicar el corpus juris interame-

64 Dulitzky, Ariel E., “An Inter-American Constitutional Court? The Invention of Conventionality Control by the Inter-American Court of Human Rights", Texas International Law Journal, Estados Unidos de América, núm. 50, 2015, p. 61; Carozza, Paolo, "The Anglo-Latin Divide and the Future of the Inter-American System of Human Rights", Notre Dame Journal of International and Comparative Law, Estados Unidos de América, vol. 5, Iss. 1, artículo 6o., 2015, p. 161.

65 Corte IDH. Caso Trabajadores Cesados del Congreso (Aguado Alfaro y otros) vs. Perú..., cit., pfo. 128.

66 Dulitzky, Ariel E., “An Inter-American...”, cit., nota 64, pp. 60 y 61. 
ricano en una actitud garantista, lo que implica, por ejemplo, interpretar el derecho nacional de manera que no vulnere derechos humanos; pero en lo que respecta a la inaplicación de normas inconvencionales (que es el aspecto más estricto de esta doctrina), las autoridades nacionales sólo podrán ejercer el control de convencionalidad en el marco de autoridad que le reconozca el derecho nacional.

\section{La jerarquía constitucional del corpus juris interamericano y la regulación de los derechos humanos en el ámbito interno}

En la hipótesis sostenida en este trabajo, el segundo elemento que afecta la operatividad del control de convencionalidad a nivel nacional está determinado por el nivel de incorporación del corpus juris interamericano en los diferentes ordenamientos jurídicos de los Estados parte de la Convención Americana. Si el control de convencionalidad no está sustentado sobre la base del principio de integración, entonces las normas que determinan la jerarquía constitucional de la Convención Americana, de otros tratados en el sistema interamericano, y de las interpretaciones de la Corte, son relevantes para determinar el nivel de intensidad del control de convencionalidad en un Estado determinado. Así, por ejemplo, la intensidad de la obligación de las autoridades de realizar un control de convencionalidad debe ser entendida de manera diferente en Guatemala, cuya Constitución reconoce el principio general relativo a que en materia de derechos humanos los tratados y convenciones aceptados y ratificados por el Estado tienen preminencia sobre el derecho interno, ${ }^{67}$ que en El Salvador, cuya Constitución reconoce la supra legalidad de los tratados de derechos humanos pero prohíbe la ratificación de tratados contrarios a la Constitución. ${ }^{68}$

En el mismo sentido, el nivel de reconocimiento que los Estados le otorgan a las interpretaciones de la Corte Interamericana como derecho nacional debe afectar la operatividad del control de convencionalidad. De esta forma, la obligación de las autoridades de "tomar en consideración" (utilizando el lenguaje del párrafo 124 de Almonacid Arellano) las interpretaciones de la Corte debe ser mayor en aquellos Estados que reconocen dichas interpretaciones como parte de su bloque de constitucionalidad, que en los Estados

\footnotetext{
67 Constitución Política de la República de Guatemala, artículo 46.

68 Constitución Política de la República de El Salvador, artículos 144, 145 y 149.
} 
que no lo hacen. Conforme al artículo 2o. de la Convención Americana, los Estados tienen libertad de decidir el nivel de incorporación de las fuentes del derecho internacional como derecho nacional, y por esa razón un Estado puede decidir legítimamente si las interpretaciones de la Corte tienen el mismo rango que la Constitución, como es el caso de Costa Rica; ${ }^{69}$ pero otro Estado puede decidir legítimamente que la jurisprudencia de la Corte es un criterio hermenéutico relevante, no decisivo, para determinar la protección de derechos humanos a nivel nacional, como es el caso de Colombia. ${ }^{70}$ Estas diferencias pueden ser sutiles y, sin embargo, deben ser seriamente tomadas en consideración para tener un entendimiento adecuado de la forma en que el control de convencionalidad opera en un Estado en particular.

Las razones por las que los Estados gozan de libertad para controlar la jerarquía de las normas internacionales en sus ordenamientos jurídicos va más allá de tecnicismos legales. ${ }^{71}$ La protección a principios como la autodeterminación, la democracia y la rendición de cuentas es relevante para sostener la libertad de los Estados contra la supremacía de las instituciones internacionales, las cuales no siempre están sujetas a los controles políticos, democráticos y constitucionales que las autoridades nacionales ejercen sobre la base de otros principios al reiterar la separación de poderes y el Estado de derecho. Por ende, es razonable asumir que los poderes del Estado mantengan la capacidad de incidir en la forma en que las fuentes del derecho internacional operan en un ordenamiento jurídico determinado, en el caso de Latinoamérica, aun después de la creación de la doctrina del control de convencionalidad. El déficit de legitimidad democrática y la debilidad de los controles políticos de los diferentes órganos que componen la Organización de Estados Americanos, hacen particularmente problemático aceptar posiciones monistas sobre la relación entre el derecho internacional y el nacional, así como entre las instituciones internacionales y las nacionales.

Algo parecido sucede con el contenido sustantivo de los derechos humanos, el cual fue mencionado en la introducción a este trabajo como el tercer elemento que afecta la operatividad del control de convencionalidad a nivel

69 Sentencia del 9 de mayo de 1995 emitida por la Sala Constitucional de la Corte Suprema de Justicia de Costa Rica. Acción Inconstitucional, voto 2313-95 (expediente 0421-S-90).

70 Sentencia C-010/00 emitida por la Corte Constitucional de Colombia.

71 Feldman, David, "Monism, Dualism and Constitutional Legitimacy", Australian YBIL, 20, pp. 106-109; Carozza, Paolo, “The Anglo-Latin...”, cit., p. 164. 
nacional. Las normas de derecho internacional de los derechos humanos fueron creadas en atención a la inherente tensión que existe entre afirmar la existencia de una regulación universal o regional de los derechos humanos, con la evidente existencia de diferencias legales y culturales en un mundo plural. ${ }^{72}$ Estas diferencias se ven reflejadas en los textos constitucionales, las leyes y las decisiones judiciales de los diferentes Estados. Por lo que, a menos que aceptemos la hipótesis que sostiene y promueve la supremacía del derecho internacional en materia de derechos humanos, es razonable suponer que existe espacio para la autodeterminación constitucional en la definición sustantiva de los derechos. ${ }^{73}$ Esto va más allá de afirmar que el derecho internacional establece el "piso" y no el "techo" de los derechos (porque ese "piso" es indudablemente cada vez más amplio, sobre todo a través de las interpretaciones que hacen las instituciones internacionales), y abriría la puerta a discutir con seriedad sobre la existencia de diferencias legítimas en la regulación de aquellos derechos que no son absolutos y donde no existe consenso claro sobre sus alcances (como sucedería, por ejemplo, en materias controversiales como los derechos económicos, sociales y culturales, los derechos sexuales y reproductivos, o los derechos de los pueblos indígenas, entre otros).

En consecuencia, el entendimiento de la intensidad del control de convencionalidad debe depender, en lo que respecta a los parámetros sobre los que se efectúa dicho control, del lugar que ocupen las distintas fuentes del corpus juris interamericano en un ordenamiento jurídico determinado. Por lo que el control de convencionalidad no debe operar de la misma manera en Panamá que en Argentina, pues ambos países tienen distintos sistemas de control de constitucionalidad, y distintas reglas de incorporación del derecho internacional de los derechos humanos. Panamá no tiene un sistema de control difuso de constitucionalidad, y las normas derivadas del derecho de los

72 Declaración Universal de los Derechos Humanos, adoptada y proclamada por la Resolución de la Asamblea General de las Naciones Unidas número 217 A iii) de 10 de diciembre de 1948, "Preámbulo"; González Domínguez, Pablo, "Reconfiguración de la relación entre el derecho internacional y el derecho nacional sobre la base del principio de subsidiariedad", Anuario Mexicano de Derecho Internacional, vol. XVII, 2017, pp. 734-742 [en este trabajo se desarrollaron las razones que sustentan esta afirmación].

73 Glendon, Mary Ann, A World Made New. Eleonor Roosevelt and the Universal Declaration of Human Rights, Nueva York, Random House, 2001, p. 221; Carozza, Paolo G. y González, Pablo, "The Final Word? Constitutional Dialogue and the Inter-American Court of Human Rights: A reply to Jorge Contesse”, I CON, vol. 15, núm. 2, 2017,p. 437. 
tratados no tienen jerarquía constitucional. ${ }^{74}$ Argentina tiene un sistema de control difuso de constitucionalidad, y la Constitución reconoce la jerarquía constitucional de la Convención Americana y otros tratados de derechos humanos. ${ }^{75}$ Lo mismo sucede con la regulación de algunos derechos en el ámbito constitucional que adquieren dimensiones distintas en cada Estado. Estas diferencias importan a un nivel normativo, pues no existe una regla de derecho internacional que requiera homogeneidad en relación al nivel de incorporación del derecho internacional a nivel nacional.

\section{El CASO DE MÉXICO}

Las transformaciones ocurridas en el ordenamiento jurídico mexicano son un buen ejemplo para mostrar cómo la intensidad del control de convencionalidad está íntimamente relacionada con la existencia de normas y principios definidos en el ámbito nacional. ${ }^{76}$ La reforma constitucional de $2011,{ }^{77}$ la adopción de la nueva ley de amparo, ${ }^{78}$ y algunas decisiones de la Suprema Corte de Justicia de la Nación (SCJN), ${ }^{79}$ abrieron la puerta

74 Constitución Política de Panamá, artículos 165 y 203; Brewer Carias, Allan, "El sistema panameño de control concentrado de la constitucionalidad en el derecho comparado", artículo presentado en las Segundas Jornadas de Derecho Procesal Jorge P., 1995, p. 5; también publicado en Registro Judicial, Publicación del Órgano Judicial de la República de Panamá, enero de 1997, pp. I-XXII, y febrero de 1997, pp. I-XXVI.

75 Highton, Elena I., "Sistema concentrado y difuso de control de constitucionalidad", en Bogdandy, Armin von et al. (coords.), La justicia constitucional y su internacionalización: ¿hacia un ius constitutionale commune en América Latina?, Max Plank Institute-IIDPC-UNAM, Instituto de Investigaciones Jurídicas, vol. I, 2010, p. 152.

76 La apertura de México al tema de la implementación de estándares en materia de derechos humanos es relativamente reciente y se debió en gran medida a la denominada "reforma constitucional en materia de derechos humanos", la cual fue publicada el 6 y 10 de junio de 2011. Respecto a un análisis de esta reforma, véase en general: Carbonell, Miguel y Salazar, Pedro (coords.), La reforma constitucional de derechos humanos. Un nuevo paradigma, México, Porrúa, 2012.

77 Constitución Política de los Estados Unidos Mexicanos, publicada en el Diario Oficial de la Federación el 5 de febrero de 1917, artículo 10.

78 Ley de Amparo, reglamentaria de los artículos 103 y 107 de la Constitución Política de los Estados Unidos Mexicanos.

79 Expediente Varios 912/10, derivado de la consulta a trámite presentada por el entonces ministro presidente, Guillermo I. Ortiz Mayagoitia, en el expediente Varios 489/2010, Suprema Corte de Justicia de la Nación; Contradicción de tesis 293/2011, entre las sustentadas por el Primer Tribunal Colegiado en materias administrativa y del trabajo 
para una amplia incorporación del corpus juris interamericano a nivel nacional, y para que se aceptara y definiera la existencia de una obligación de todas las autoridades nacionales para ejercer un control de convencionalidad. Pero la apertura del ordenamiento jurídico mexicano no sucedió de manera automática con la ratificación de la Convención Americana, o porque México fue condenado en la sentencia Radilla Pacheco vs. México (2009), o bien por la convicción ideológica de los legisladores o los ministros de la SCJN. Es razonable suponer que la aceptación del control de convencionalidad está conectado con múltiples factores normativos y políticos, tanto internacionales como nacionales.

Sin la intensión de ser exhaustivo, pues no es el objeto de este trabajo, tres factores son relevantes para explicar la apertura del sistema jurídico mexicano a la Convención Americana y a la adopción de la doctrina del control de convencionalidad. El primer factor es el reconocimiento de rango constitucional de las normas de derechos humanos previstas en los tratados internacionales, y la existencia de herramientas reconocidas a nivel constitucional que favorecen su efectiva aplicación por parte de los operadores jurídicos nacionales. ${ }^{80}$ Estas herramientas incluyen: el principio de interpretación conforme; el principio pro persona; el reconocimiento de los principios de universalidad, interdependencia, indivisibilidad y progresividad; y el reconocimiento de la obligaciones de prevención, investigación, sanción y reparación de las violaciones a los derechos humanos. ${ }^{81}$ El núcleo de la apertura amplia a la implementación de la Convención Americana se encuentra reflejado en el artículo 1o. de la Constitución Política de los Estados Unidos Mexicanos, que a la letra dice:

Artículo 1o. En los Estados Unidos Mexicanos todas las personas gozarán de los derechos humanos reconocidos en esta Constitución y en los tratados internacionales de los que el Estado mexicano sea parte, así como de las garantías para su protección, cuyo ejercicio no podrá restringirse ni suspenderse, salvo en los casos y bajo las condiciones que esta Constitución establece.

Las normas relativas a los derechos humanos se interpretarán de conformidad con esta Constitución y con los tratados internacionales de la

del Décimo Primer Circuito y el Séptimo Tribunal Colegiado en materia Civil y Administrativa, Suprema Corte de Justicia de la Nación.

80 Cfr. Constitución Política de los Estados Unidos Mexicanos, cit., nota 77, artículo 1o.

81 Idem. 
materia favoreciendo en todo tiempo a las personas la protección más amplia. Todas las autoridades, en el ámbito de sus competencias, tienen la obligación de promover, respetar, proteger y garantizar los derechos humanos de conformidad con los principios de universalidad, interdependencia, indivisibilidad y progresividad. En consecuencia, el Estado deberá prevenir, investigar, sancionar y reparar las violaciones a los derechos humanos, en los términos que establezca la ley.

Queda prohibida toda discriminación motivada por origen étnico o nacional, el género, la edad, las discapacidades, la condición social, las condiciones de salud, la religión, las opiniones, las preferencias sexuales, el estado civil o cualquier otra que atente contra la dignidad humana y tenga por objeto anular o menoscabar los derechos y libertades de las personas. $^{82}$

Cabe destacar dos cuestiones relativas al artículo 1o. de la Constitución después de la reforma constitucional de 2011. La primera es que, al situar a las normas de derechos humanos en la cúspide de la jerarquía normativa del sistema jurídico mexicano, la Constitución mexicana permite - en principio - que cualquier conflicto entre normas que no involucre a la propia Constitución deba resolverse a favor de la norma de derechos humanos de fuente internacional. Esta posición se ve fortalecida por lo establecido en el artículo 133 de la Constitución, relativo a la obligación de los jueces del Estado (lato sensu) de cumplir con lo establecido en la Constitución, las leyes del Congreso y los tratados internacionales. ${ }^{83}$ Por otro lado, el principio de interpretación conforme, y el principio pro personae, establecen pautas hermenéuticas que permiten que las normas constitucionales - y en general de todo el sistema jurídico- se armonicen con el derecho internacional de los derechos humanos, pero también permite que las interpretaciones de los operadores de justicia se maximicen tomando en consideración la norma que otorgue una mayor protección de derechos, ya sea ésta de fuente nacional o de fuente internacional. ${ }^{84}$

\footnotetext{
82 Idem, artículo 1 o.

83 Ibidem, artículo 133.

84 Cfr. Tinoco, Jorge Ulises, "La reforma y las normas de derechos humanos previstas en los tratados internacionales", en Carbonell, Miguel, y Salazar, Pedro (coords.), La reforma..., cit., pp. 44-46.
} 
El segundo factor es el artículo 103, fracción I, del texto constitucional mexicano, el cual prevé la procedencia del amparo "por normas generales, actos u omisiones de la autoridad que violen los derechos humanos reconocidos y las garantías otorgadas para su protección por esta Constitución, así como por los tratados internacionales de los que el Estado mexicano sea parte". ${ }^{85} \mathrm{El}$ amparo es la institución fundamental de control constitucional y de protección de los derechos humanos en el ordenamiento jurídico mexicano. Hasta hace pocos años se entendía que sólo se podía utilizar este mecanismo de protección contra "leyes o actos de autoridad que violen las garantías individuales", ${ }^{86}$ pero el texto vigente de la Constitución mexicana ha ampliado esta protección de forma tal que existe un "espacio lo suficientemente dúctil, grande y efectivo, para hacer valer cualquier posible violación de derechos humanos" - incluidos, por supuesto, los derechos humanos de fuente internacional- ${ }^{87}$ La nueva Ley de Amparo sigue la misma lógica, constituyéndose así como un "juicio de derechos fundamentales" que protege derechos humanos constitucionalizados (tanto de origen nacional como internacional). ${ }^{88}$

El tercer factor tiene una fuente jurisprudencial, pues fue desarrollado por la Suprema Corte de Justicia de la Nación (SCJN) al decidir sobre el cumplimiento de sentencia en Radilla. ${ }^{89}$ En esta decisión, la SCJN, apoyada en los elementos constitucionales antes mencionados, y en consideración de las obligaciones dirigidas al Poder Judicial en virtud de la sentencia en Radilla, realizó interpretaciones constitucionales que son fundamentales para entender el funcionamiento del control de convencionalidad en el sistema jurídico mexicano. En particular, la SCJN reconoció la existencia de una obligación a cargo de todos los jueces mexicanos de realizar un control de convencionalidad en los términos establecidos por la Corte Interameri-

\footnotetext{
85 Constitución Política de los Estados Unidos Mexicanos, cit., nota 77, artículo 103-I.

86 El término garantías individuales se refiere a los derechos fundamentales de fuente constitucional.

87 Rosario, Marcos del y Gil Rendón, Raymundo, "El juicio de amparo a la luz de la reforma constitucional de 2011", UNAM, Biblioteca Jurídica Virtual del Instituto de Investigaciones Jurídicas, p. 67, disponible en: http://www.juridicas.unam.mx/publica/librev / rev/qdiuris/cont/15/cnt/cnt4.pdf(consultada el 29 de abril de 2014).

88 Cfr. Ferrer Mac-Gregor, Eduardo y Sánchez Gil, Rubén, El nuevo juicio de amparo. Guía de la reforma constitucional y la nueva Ley de Amparo, México, Porrúa, 2013, pp. 4, 5 y 76.

89 Expediente Varios 912/10..., cit.
} 
cana en su jurisprudencia. Este criterio implicó una nueva interpretación del artículo 133 de la Constitución, la cual abrió la puerta para que todos los jueces nacionales realizaran un control difuso de constitucionalidad y convencionalidad, lo que les permite desaplicar al caso concreto la norma inconstitucional pero sin realizar una declaración de invalidez, la cual es una facultad reservada a los tribunales federales. ${ }^{90}$

En el Expediente Varios 912/10 la SCJN modificó algunas características particulares del sistema jurídico mexicano en materia de control de constitucionalidad (el cual es un sistema mixto, que tradicionalmente excluyó a los jueces locales de esta función), para incrementar la intensidad de las obligaciones establecidas en virtud del control de convencionalidad como fue formulado por la Corte Interamericana. ${ }^{91}$ En la misma lógica de adaptación del derecho internacional al derecho nacional y viceversa (o de construcción de "puentes", utilizando la metáfora de García Ramírez), la SCJN estableció que el control de convencionalidad "en ningún momento supone la eliminación o el desconocimiento de la presunción de constitucionalidad de las leyes, sino que, precisamente, parte de esta presunción al permitir hacer el contraste previo a su aplicación", y de esta forma definió tres pasos específicos que los jueces deberán seguir cuando realicen un control de convencionalidad:

a) Interpretación conforme en sentido amplio. Ello significa que los jueces del país, al igual que todas las demás autoridades del Estado mexicano, deben interpretar el orden jurídico a la luz y conforme a los derechos humanos establecidos en la Constitución y en los tratados internacionales en los cuales el Estado mexicano sea parte, favoreciendo en todo tiempo a las personas la protección más amplia.

b) Interpretación conforme en sentido estricto. Ello significa que cuando hay varias interpretaciones jurídicamente válidas, los jueces deben, partiendo de la presunción de constitucionalidad de las leyes, preferir aquella que hace a la ley acorde con los derechos humanos establecidos en la Constitución y en los tratados internacionales en

\footnotetext{
90 Idem.

91 Ferrer Mac-Gregor, Eduardo, "Interpretación conforme y control difuso de convencionalidad. El nuevo paradigma del juez mexicano", en Carbonell, Miguel, y Salazar, Pedro (coords.), La reforma..., cit., p. 405; Expediente Varios 912/10, ibidem, nota 79.
} 
los que el Estado mexicano sea parte, para evitar que se incida o se vulnere el contenido esencial de estos derechos.

c) Inaplicación de la ley cuando las alternativas anteriores no son posibles. Ello no afecta o rompe con la lógica del principio de división de poderes y del federalismo, sino que fortalece el papel de los jueces al ser el último recurso para asegurar la primacía y aplicación efectiva de los derechos humanos establecidos en la Constitución y en los tratados internacionales de los cuales el Estado mexicano es parte. $^{92}$

En el mismo sentido, la SCJN estableció en la Contradicción de Tesis 293/2011 que la jurisprudencia de la Corte Interamericana es vinculante para los jueces mexicanos, siempre que ésta sea más favorable a la persona. ${ }^{93}$ Este criterio es válido incluso si se trata de estándares desarrollados en casos donde el Estado mexicano no haya sido parte del litigio, lo cual implica un reconocimiento de la relevancia constitucional que tienen las interpretaciones de la Corte Interamericana como precedentes. ${ }^{94} \mathrm{La}$ única excepción a este principio parece que es en casos donde la Constitución mexicana establezca una restricción expresa al ejercicio de un derecho, ${ }^{95}$ la cual ha sido una posición criticada por la Comisión Interamericana de Derechos Humanos, ${ }^{96}$ pero que es jurídicamente obligatoria para las autoridades mexicanas. El fundamento legal de ambos criterios es el propio artículo 1o. de la Constitución mexicana, pues la SCJN consideró que el principio pro persona obliga a los jueces nacionales a realizar la interpretación más favorable, pero siempre que no exista una restricción expresa en el texto constitucional. ${ }^{97}$ Sobre estas bases se estableció que los jueces nacionales deberán atenerse al siguiente criterio cuando utilicen las interpretaciones

92 Expediente Varios 912/10, ibidem, pfo. 33.

93 Contradicción de tesis $293 / 2011 \ldots$, cit.

94 Idem. Jurisprudencia emitida por la Corte Interamericana de Derechos Humanos. Es vinculante para los jueces mexicanos siempre que sea más favorable a la persona.

95 Idem. Derechos humanos contenidos en la Constitución y en los tratados internacionales. Constituyen el parámetro de control de regularidad constitucional, pero cuando en la Constitución haya una restricción expresa al ejercicio de aquéllos, se debe estar a lo que establece el texto constitucional.

96 Comisión Interamericana de Derechos Humanos, situación de los derechos humanos en México, OEA/Ser. L/V/II.Doc. 44/15, 31 de diciembre 2015, pfo. 83.

97 Contradicción de tesis $293 / 2011 \ldots$, cit. 
de la Corte Interamericana como parámetro para el ejercicio del control de convencionalidad: a) cuando el criterio se haya emitido en un caso en el que el Estado mexicano no haya sido parte, la aplicabilidad del precedente al caso específico debe determinarse con base en la verificación de la existencia de las mismas razones que motivaron el pronunciamiento; $b$ ) en todos los casos en que sea posible debe armonizarse la jurisprudencia interamericana con la nacional, y c) de ser imposible la armonización, debe aplicarse el criterio que resulte más favorecedor para la protección de los derechos humanos..$^{98}$

Es verdad que la intensidad del control de convencionalidad en el sistema jurídico mexicano está directamente relacionado con la forma en que los ministros de la SCJN decidieron cumplir con la sentencia de la Corte Interamericana en el caso Radilla Pacheco y con las decisiones posteriores que adoptaron en la materia. Los ministros bien pudieron tomar una dirección diferente cuando definieron los alcances del control de convencionalidad, por ejemplo, estableciendo que su ejercicio sólo obliga a declinar la jurisdicción militar en aquellos casos que involucren violaciones a los derechos humanos cometidos por miembros de las fuerzas armadas. Pero también es cierto que la decisión de la SCJN desde el Expediente Varios 912/10 y en la Contradicción de Tesis 293/2011 es acorde con la tendencia constitucional iniciada con las reformas de 2011 y la Ley de Amparo de 2013.

La adopción de dichas normas constitucionales y reglamentarias es un ejemplo sobre cómo la doctrina del control de convencionalidad está íntimamente relacionada con el derecho constitucional de los Estados, el cual regula aspectos específicos sobre cómo este control deberá ser realizado por las autoridades nacionales. Es razonable pensar que estas regulaciones variarán de un Estado a otro, precisamente por el pluralismo jurídico intrínseco en el derecho internacional de los derechos humanos.

98 Idem. 


\section{CONCLUSIÓN}

El control de convencionalidad está íntimamente conectado con el derecho nacional, tanto desde una perspectiva descriptiva como prescriptiva. Desde una perspectiva descriptiva, el control de convencionalidad refleja y reafirma algunas de las recientes transformaciones del constitucionalismo latinoamericano en los últimos 30 años. Estas transformaciones abrieron la puerta a la incorporación del derecho internacional de los derechos humanos a los ordenamientos jurídicos nacionales, y al reconocimiento de los jueces como los primeros garantes de los derechos humanos a nivel nacional.

Desde una perspectiva normativa, el control de convencionalidad está conectado con el derecho nacional en un aspecto fundamental: las autoridades nacionales deben ejercer control de convencionalidad en el marco de sus respectivas competencias, y conforme a las regulaciones procesales correspondientes, las cuales están enteramente definidas por el derecho nacional. Este trabajo además ha sostenido la hipótesis de que el control de convencionalidad está también relacionado normativamente con el lugar que ocupa el corpus juris interamericano a nivel nacional, y con el nivel de regulación de los derechos humanos a nivel constitucional, pues no es posible afirmar a priori que las normas de derecho internacional son supremas al derecho nacional.

La conexión normativa entre el control de convencionalidad y el derecho nacional conduce a una conclusión final: la operatividad de esta doctrina será legítimamente distinta en cada Estado parte de la Convención Americana, pues existen legítimas diferencias en la manera en que los Estados reconocen competencias a sus autoridades (especialmente a sus jueces), porque existen diferentes niveles de reconocimiento del corpus juris interamericano en el derecho nacional de los Estados (algunos le reconocen grado supraconstitucional a las normas internacionales de derechos humanos, pero otros no), y porque existen distintos niveles de protección a los derechos humanos en el ámbito interno.

Lo anterior significa que la intensidad del control de convencionalidad dependerá de la existencia de los "puentes" que cada Estado ha tendido para incrementar (o disminuir) la implementación del corpus juris interamericano a nivel nacional, y del rol que jueguen las autoridades nacionales (en especial los jueces) como garantes de los derechos humanos. La construcción de 
puentes es realizada de manera subsidiaria por actores nacionales e internacionales y, por lo tanto, el entendimiento del control de convencionalidad y su aplicación cotidiana debe hacerse sobre las bases del derecho nacional y del derecho internacional tomadas en su conjunto. ${ }^{99}$

\footnotetext{
99 González Domínguez, Pablo et al., La doctrina del control de convencionalidad y su aplicación en algunas experiencias nacionales, Chile, Centro de Estudios de Justicia de las Américas, 2016, pp. 41-47. En este trabajo se plantea una metodología específica sobre las consideraciones que las autoridades nacionales deben tener en el ejercicio del control de convencionalidad, así como una serie de propuestas para incrementar su efectividad en el ámbito nacional,disponible en: http://biblioteca.cejamericas.org/hand le/2015/5497.
}

Fecha de recepción: 2 de mayo de 2016.

Fecha de dictamen: 15 de abril de 2017. 